\title{
Understanding Cu-Alumina Interactions in Redox Conditions for Chemical Looping Combustion (CLC) Application - A Multi-scale Correlative Electron and X-Ray Microscopy Study
}

$\underline{\text { Sharmin Sharna }}^{1,2}{ }^{,}$, Arnold Lambert ${ }^{1}$, Virgile Rouchon ${ }^{1}$, Christèle Legens ${ }^{1}$, Anne-Lise Taleb ${ }^{1}$, Stefan Stanescu $^{3}$, David Chiche ${ }^{1}$, Anne-Sophie Gay ${ }^{1}$, and Ovidiu Ersen ${ }^{2}$

${ }^{1}$ IFP Energies nouvelles, Rond-point de l'échangeur de Solaize, BP 3, 69360 Solaize, France.

${ }^{2}$ Institut de Physique et de Chimie des Matériaux de Strasbourg, UMR 7504 CNRS - Université de Strasbourg, 67034 Strasbourg, France.

${ }^{3}$ Synchrotron Soleil, l'Orme des Merisiers, BP48 Saint-Aubin, 91192 Gif-sur-Yvette, France.

Chemical Looping Combustion (CLC) is a midterm solution for fossil fuel utilization with inherent carbon dioxide capture, based on the use of an oxygen carrier material. The oxygen carriers (OC) replace air to provide oxygen to a wide range of fuels for combustion, via reduction/oxidation cycles in a circulating fluidized bed reactor at high temperature [1]. Copper oxide supported on alumina grain $\left(\mathrm{CuO} / \mathrm{Al}_{2} \mathrm{O}_{3}\right)$ has been widely considered as a promising oxygen carrier (OC) for industrial use in CLC, due to its benign nature and flexible redox behaviour that ensures high reactivity and oxygen transfer capacity. However, the OC sustains successive high temperature $\left(800-900^{\circ} \mathrm{C}\right)$ reduction (combustion) and oxidation (regeneration of oxide phase) reaction cycles which lead to chemical and morphological changes in the material causing the degradation in the oxygen-carrying properties. The evolution in the cycled material is attributed to the diffusion of the $\mathrm{Cu}$-phases at the grain scale [2]. Herein, we are bridging the gap in understanding between the observed $\mu \mathrm{m}$-scale migration of $\mathrm{Cu}$-based phases and nanoscale transformations of the $\mathrm{Cu}$ nanoparticles (NPs) by employing a multi-scale characterization approach using Scanning Transmission X-ray (STXM) and Scanning Transmission Electron (STEM) Microscopies, respectively.

We have studied $13 \mathrm{wt} \% \mathrm{CuO}$ supported on $50-100 \mu \mathrm{m}$ sized $\gamma-\mathrm{Al}_{2} \mathrm{O}_{3}$ grain produced via incipient wetness impregnation, calcined at 800 and $900{ }^{\circ} \mathrm{C}$. To mimic the CLC cycling, the fresh samples were subjected to oxidation and reduction under air and $\mathrm{H}_{2}$ at $900{ }^{\circ} \mathrm{C}$, in a thermogravimetric analyser (TGA). Ultramicrotomy sections of $100 \mathrm{~nm}$ thickness were prepared for SEM, STXM and TEM characterizations. Energy stacks and mappings were performed at the $\mathrm{Cu}$ L-edge and Al K-edge to identify the specific spectral features of each compound. In situ TEM was performed using a probe Cs-corrected microscope equipped with Protochips" "Atmosphere" in situ gas setup with sealed environmental cell (e-Cell), operating at atmospheric pressure.

The fresh grains are composed of $\gamma-\mathrm{Al}_{2} \mathrm{O}_{3}$ with homogeneously dispersed $\mathrm{CuO}$ nanoparticles $(10-20 \mathrm{~nm})$. With progressive cycling (after 50 redox cycles), at the grain scale $(\mu \mathrm{m})$, we observe the propagation of gamma to alpha reaction front in the solids (Figure 1). At a smaller scale $\left(10 \times 10 \mu \mathrm{m}^{2}\right)$, this front displays a well-defined structural-chemical gradient characterized by (Figure 1): zone 1, non-stoichiometric $\mathrm{Cu}$ (II) aluminate; zone 2, an intermediate thin layer $(<200 \mathrm{~nm})$ of $\mathrm{Cu}$ (II) aluminate, enriched in Cu compared to zone 1; zone 3, $\alpha-\mathrm{Al}_{2} \mathrm{O}_{3}$ phase containing large $\mathrm{CuO}$ particles. The proportion of copper shows a strong variation from $10 \mathrm{wt} \% \mathrm{Cu}$ in zone 1 , to $\sim 25 \mathrm{wt} \%$ at the edge of the reaction front in zone 2 . In addition, in- situ STEM observation at $900{ }^{\circ} \mathrm{C}$ under $\mathrm{H}_{2}$-reduction have shown the migration of copper to form copper nanoparticles from a starting oxidized sample mainly composed of homogeneous $\mathrm{Cu}$ (II) aluminate (Figure 2). It is suspected that the expelling of $\mathrm{Cu}$ from the spinel structure of $\mathrm{Cu}$ (II) aluminate favours 
the formation of the $\alpha-\mathrm{Al}_{2} \mathrm{O}_{3}$. This suggests that the mobility of copper during redox cycling is linked to the phase transition of $\gamma$ to $\alpha-\mathrm{Al}_{2} \mathrm{O}_{3}$. However, the $\gamma$ to $\alpha-\mathrm{Al}_{2} \mathrm{O}_{3}$ transition is not favoured in the pure $\mathrm{Al}-$ O system below $1000-1100{ }^{\circ} \mathrm{C}$ [3]. Reversely, the oxidative formation of spinel is only possible in the $\mathrm{CuO}+\gamma-\mathrm{Al}_{2} \mathrm{O}_{3}$ system and thermodynamically limited in the case of $\mathrm{CuO}+\alpha-\mathrm{Al}_{2} \mathrm{O}_{3}$, at $900{ }^{\circ} \mathrm{C}$ [4]. To minimize the energy of the system, the mobility of copper on alumina during oxidation is sufficient to either form (1) $\mathrm{CuAl}_{2} \mathrm{O}_{4}$ at the expense of $\gamma-\mathrm{Al}_{2} \mathrm{O}_{3}$, and (2) larger $\mathrm{CuO}$ particles on $\alpha-\mathrm{Al}_{2} \mathrm{O}_{3}$, by sintering. This study demonstrates the utilization of correlative multi-scale imaging techniques to reveal the dynamic interactions of metal/metal oxides and ceramic supports in complex reactive systems.

\section{References:}

[1] J Adanez et al, Progress in Energy and Combustion Science 38 (2012), p. 215.

[2] A Lambert et al, Fuel. 216 (2018), p. 71.

[3] A Boumaza et al, Journal of Solid-State Chemistry 182 (2009), p. 1171.

[4] W Hu et al, RSC Adv. 6 (2016), p. 113016.

[5] The authors acknowledge IFP Energies Nouvelles for the funding of this study.

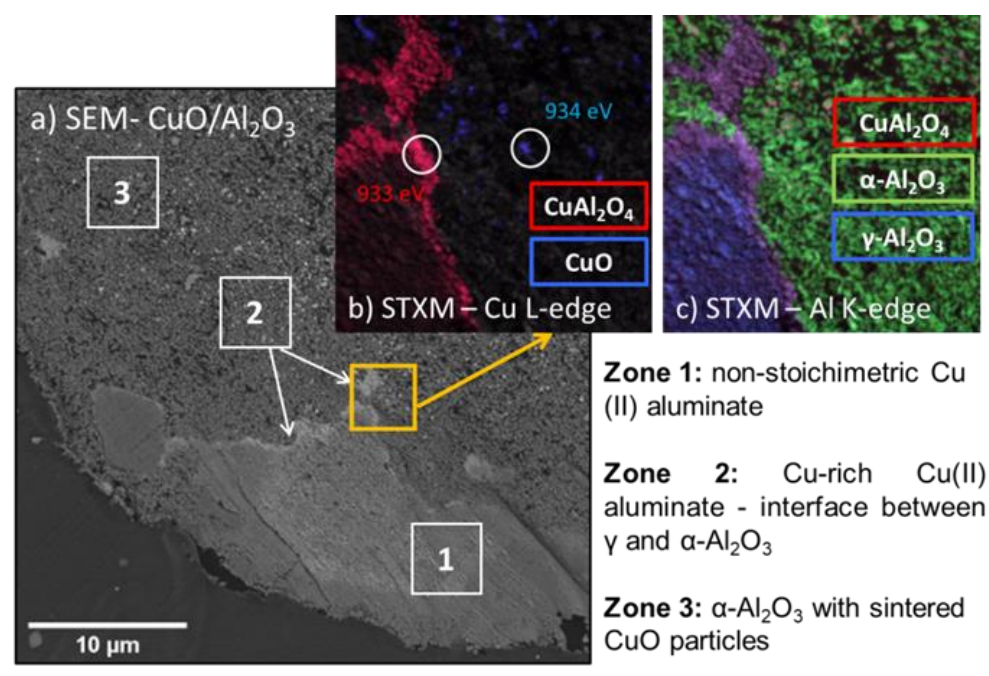

Figure 1. a) SEM image of ultramicrotomy cut of $\mathrm{CuO} / \mathrm{Al}_{2} \mathrm{O}_{3}$ after 50 cycles, 10 x $10 \mu \mathrm{m} \mathrm{STXM} \mathrm{map} \mathrm{of}$ the area represented by the yellow square at b) $\mathrm{Cu}$ L-edge and c) Al K-edge.

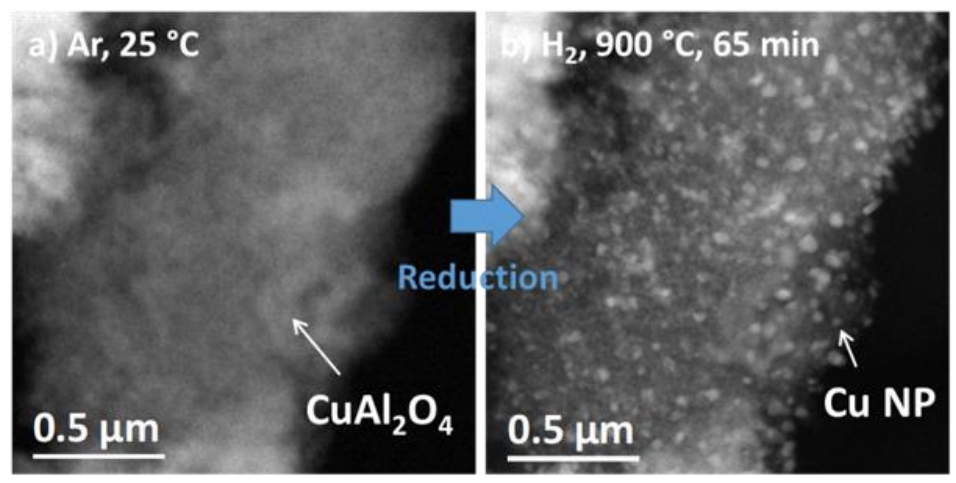

Figure 2. In-situ STEM characterisation of $\mathrm{CuO} / \mathrm{Al}_{2} \mathrm{O}_{3} \mathrm{OC}$ with starting phase containing $\mathrm{CuAl}_{2} \mathrm{O}_{4}$ under Ar atmosphere at $25{ }^{\circ} \mathrm{C}$ and b) after reduction by $\mathrm{H}_{2}$. 